\title{
Storm-time related mass density anomalies in the polar cap as observed by CHAMP
}

\author{
R. Liu ${ }^{1,2}$, H. Lühr ${ }^{1}$, and S.-Y. Ma ${ }^{2}$ \\ ${ }^{1}$ Helmholtz Centre Potsdam, GFZ German Research Centre for Geosciences, Telegrafenberg, 14473 Potsdam, Germany \\ ${ }^{2}$ Dept. of Space Physics, College of Electronic Information, Wuhan University, Wuhan 430079, China \\ Received: 17 July 2009 - Revised: 8 January 2010 - Accepted: 11 January 2010 - Published: 19 January 2010
}

\begin{abstract}
Strong and localized thermospheric mass density events are observed in the polar cap region by the CHAMP satellites at about $400 \mathrm{~km}$ altitude during geomagnetic storms. During the 4 years considered (2002-2005) 29 storms with Dst $<-100 \mathrm{nT}$ occurred, in $90 \%$ of them polar cap density anomalies were detected. Based on the altogether 56 anomaly events a statistical analysis was performed. The anomalies are of medium scale $(500-1500 \mathrm{~km})$ and seem to have a short dwell-time $(<1.5 \mathrm{~h})$ in the polar cap. The relative density enhancement is found to range around 2 in both hemispheres. The peak density is in the Northern Hemisphere by a factor of 1.4 larger than in the southern. Also the number of detected events in the north is twice as large as that in the south (37 vs. 19). Mass density anomalies in the polar cap occur under all interplanetary magnetic field (IMF) directions. Numerous strong anomalies have been detected in positive and negative IMF $B_{\mathrm{Z}}$ conditions when the magnetic field strength is above $5 \mathrm{nT}$. Rather few events occurred for small $\left|B_{\mathrm{Z}}\right|(<5 \mathrm{nT})$ or for positive $B_{\mathrm{Z}}$ combined with vanishing $B_{\mathrm{y}}$. Some of the density anomalies are accompanied by intensive small-scale field-aligned currents (FACs). But about as many show no relation to FACs. If FACs are present there, the current density is believed to be correlated with the strength of the IMF $B_{\mathrm{Z}}$. Although this paper concentrates on the presentation of the observations, we show for one event that the ion outflow mechanism could be responsible for the mass density anomalies in the polar cap.
\end{abstract}

Keywords. Ionosphere (Ionosphere-atmosphere interactions) - Magnetospheric physics (Polar cap phenomena) Meteorology and atmospheric dynamics (Thermospheric dynamics)

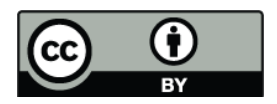

Correspondence to: R. Liu (ruosi@gfz-potsdam.de)

\section{Introduction}

The thermospheric mass density and composition experience dramatic changes globally during magnetic storms (e.g. Burns et al., 1995; Forbes et al., 1996; Prölss, 1997). The reaction of the thermosphere to changes in solar and geomagnetic conditions occurs through a series of complex processes. Storm-related inputs are deposited primarily at high magnetic latitudes in the form of Joule heating, momentum transfer by enhanced plasma convection or energetic particle precipitation. These thermospheric disturbances are propagated subsequently to lower latitudes for example via traveling atmospheric disturbances (TADs).

Only recently detailed studies of the thermospheric density have become possible by employing measurements of accelerometers such as on CHAMP and GRACE (e.g. Bruinsma et al., 2004; Liu et al., 2005). Quite a number of studies have been devoted to the study of thermospheric storm effects (e.g. Liu and Lühr, 2005; Forbes et al., 2005; Sutton et al., 2005; Bruinsma et al., 2006; Burke et al., 2007). They have revealed important responses of the mass density on global scales. As expected, the effects differ significantly from storm to storm. All these listed studies have focused on a few prominent storms of the last solar cycle, while an identification of typical features was not possible so far.

In this study we are focusing on density anomalies occurring at high latitudes. A very prominent feature in that region is the cusp-related density enhancement (Lühr et al., 2004; Schlegel et al., 2005). An extensive statistical analysis of the cusp-related density anomalies was performed by Rentz and Lühr (2008). They clearly identified the merging electric field as a suitable controlling parameter for the relative enhancement of the density at least during non-storm times. Another important finding is the hemispheric asymmetry. On average the Northern Hemisphere is more sensitive to the identical solar wind input. Rentz and Lühr (2008) exclude storms from their analysis and considered only the latitude range $60^{\circ}-80^{\circ}$ Mlat on the day side.

Published by Copernicus Publications on behalf of the European Geosciences Union. 
A detailed study about the dependence of the Southern Hemisphere high-latitude thermospheric density on the orientation of the interplanetary magnetic field (IMF) was performed by Kwak et al. (2009). By focusing on the months around the December 2001 solstice they found on average an overall enhancement of the thermospheric density for negative IMF $B_{\mathrm{z}}$. For negative IMF $B_{\mathrm{y}}$ an enhancement is reported in the early morning sector while they find a depletion in that region for positive $B_{\mathrm{y}}$. All the main density variations are preferably confined to the auroral region, whereas the polar cap remains largely featureless.

This study will focus on mass density anomalies in the polar cap occurring during magnetic storms. These have so far not been studied in sufficient depth. For our investigations we consider all magnetic storms occurring during the 4 years, 2002 to 2005. Densities derived from the CHAMP accelerometer are analyzed and interpreted for this purpose.

In the following sections, the data used and the processing applied are first introduced in Sect. 2 before some instructive examples of density anomalies are presented in Sect. 3. Section 4 presents a statistical analysis of important features deduced from the whole sample of events. In Sect. 5, the obtained results are discussed in the context of previous publications.

\section{Dataset}

The Challenging Minisatellite Payload (CHAMP) spacecraft was launched on 15 July 2000 into a circular near-polar orbit with an inclination of $87.25^{\circ}$. The orbit plane precesses at a rate of one hour in local time per 11 days, covering all the local times in 131 days. The time period considered in our present study covers complete four years from 2002 to 2005. During the four years, the orbital altitude declined from $425 \mathrm{~km}$ to $360 \mathrm{~km}$. Owing to its low altitude and the coverage of all latitudes and local times, CHAMP is very suitable for a long-term monitoring of ionospheric and thermospheric characteristics.

\subsection{CHAMP data}

The dataset we have primarily used in this paper is the Level2 data of CHAMP's STAR (Space Triaxial Accelerometer for Research missions) non-gravitational acceleration measurements. The time resolution of the data is $10 \mathrm{~s}$, which corresponds to a sampling distance of $76 \mathrm{~km}$. The data preprocessing eliminates spurious spikes, and accelerations which are caused by attitude maneuvers. Since we focus on the acceleration related to air drag, the component caused by solar radiation pressure is subtracted from the readings as well. As the spacecraft is flying, it experiences the drag force by the air pointing opposite to the flight direction. The acceleration $\boldsymbol{a}$ produced by atmospheric drag can be expressed as:

$\boldsymbol{a}=-\frac{1}{2} \rho \frac{C_{\mathrm{D}}}{m} A_{\mathrm{eff}} V^{2} \boldsymbol{v}$ the minus indicates that the spacecraft is actually decelerated by the air drag force. So the total mass density of the air, $\rho$, is given by

$\rho=-\frac{2 m \boldsymbol{a} \cdot \boldsymbol{v}}{C_{\mathrm{D}} A_{\mathrm{eff}} V^{2}}$

where $C_{\mathrm{D}}$ is the drag coefficient, $m$ the spacecraft mass, $V$ the spacecraft velocity relative to the atmosphere, and $v$ is the unit vector of the velocity in ram direction, $A_{\text {eff }}=$ $A_{\mathrm{x}} \cos \alpha+A_{\mathrm{y}} \sin |\alpha|$, is the effective cross-sectional area of the satellite with $\tan \alpha=\frac{a_{\mathrm{y}}}{a_{\mathrm{x}}}$, where $\alpha$ is the angle between the spacecraft along-track axis and the ram direction (in the $\mathrm{x}-\mathrm{y}$ plane) (Liu et al., 2005). The total velocity is $V^{2}=V_{\mathrm{x}}^{2}+V_{\mathrm{y}}^{2}$, where $V_{\mathrm{X}}$ is the spacecraft mean velocity along the orbit, which amounts to $7.62 \mathrm{~km} / \mathrm{s}$, and $V_{\mathrm{y}}$ is the wind velocity in the cross-track direction. This wind component is determined as described by Liu et al. (2006). The along-track wind is neglected. The $\mathrm{z}$ component of the accelerometer is malfunctioning on CHAMP. Therefore it is not considered. But since the vertical wind is generally small, the contribution of $a_{\mathrm{z}}$ to Eq. (2) can be regarded as negligible.

Measurements of the accelerometer are influenced by both density and wind. Errors are incurred by neglecting the intrack wind. The accuracy of derived density during high geomagnetic activities is estimated to be $10 \%-20 \%$ at high latitudes where along-track wind speeds are of order 500$750 \mathrm{~m} / \mathrm{s}$ (e.g. Lühr et al., 2007; Förster et al., 2008). In this study measurements during geomagnetic storm time are used. Therefore reduced accuracy has to be taken into account. Despite the somewhat lower accuracy, the observations still allow a significant level of physical interpretation, given that the considered density enhancements reach several hundred percent in polar cap regions during storm time.

Additional CHAMP data considered are the electron density and temperature. They are derived from Planar Langmuir Probe (PLP) measurements (Cooke et al., 2003; McNamara et al., 2007). The PLP is a $152 \times 203 \mathrm{~mm}$ rectangular plate with a $106 \times 156 \mathrm{~mm}$ sensing area, which is mounted on the lower front panel of the spacecraft. It alternatively operated at floating potential for $14 \mathrm{~s}$, to track the spacecraft potential and in voltage sweep mode for $1 \mathrm{~s}$ between -2.5 and $+2.5 \mathrm{~V}$ to measure the ion saturation current and to determine the electron temperature. Therefore both the electron density and temperature data are available only at $15 \mathrm{~s}$ intervals.

Of particular interest for this study are the field-aligned currents (FACs). These are derived from the CHAMP magnetic field measurements. The standard approach for deriving FACs from single satellite observations is

$j_{/ /}=\frac{\partial B_{\mathrm{y}}}{\mu_{0} \partial t} \cdot \frac{1}{v_{\mathrm{S} / \mathrm{C}} \sin \gamma}$,

where $B_{\mathrm{y}}$ is the magnetic field eastward component, $\mu_{0}$ the susceptibility of free space, $v_{\mathrm{S} / \mathrm{C}}$ the spacecraft velocity and $\gamma$ the angle between the current sheet and the velocity vector. We are following the approach of Wang et al. (2005) where 
Table 1. Characteristic features of the mass density anomaly events from 2002 through 2005 . Peak and relative peak density along with date, universal time (UT) and magnetic local time (MLT), geomagnetic latitude and FWHM separately for the Northern and Southern Hemisphere.

\begin{tabular}{|c|c|c|c|c|c|c|}
\hline $\begin{array}{c}\text { Date } \\
\text { (yyyymmdd) }\end{array}$ & $\begin{array}{l}\text { UT } \\
\text { (h) }\end{array}$ & $\begin{array}{l}\text { MLT } \\
\text { (h) }\end{array}$ & $\begin{array}{l}\text { Mlat } \\
\left({ }^{\circ}\right)\end{array}$ & $\begin{array}{c}\rho_{\text {peak }} \\
\left(10^{-12} \mathrm{~kg} / \mathrm{m}^{3}\right)\end{array}$ & $\begin{array}{c}\rho_{\text {rel }} \\
\left(^{\circ}\right)\end{array}$ & $\begin{array}{c}\text { FWHM } \\
(\mathrm{km})\end{array}$ \\
\hline \multicolumn{7}{|c|}{ Northern Hemisphere } \\
\hline 20020418 & 12.55 & 2.28 & 81.06 & 13.71 & 1.83 & 1012 \\
\hline 20020511 & 11.58 & 19.2 & 85.67 & 12.3 & 1.56 & 410 \\
\hline 20020523 & 13.67 & 16.03 & 84.04 & 16.61 & 1.85 & 1150 \\
\hline 20020802 & 6.02 & 8.8 & 82.38 & 5.38 & 1.58 & 520 \\
\hline 20020904 & 5.15 & 5.66 & 82.38 & 10.66 & 1.78 & 770 \\
\hline 20021004 & 0.02 & 7.65 & 85.04 & 11.15 & 1.72 & 630 \\
\hline 20021004 & 1.55 & 11.31 & 79.74 & 10.63 & 1.56 & 1090 \\
\hline 20030530 & 4.8 & 5.1 & 82.2 & 12.98 & 2.61 & 1230 \\
\hline 20030617 & 6.3 & 0.86 & 78.11 & 8.96 & 1.99 & 650 \\
\hline 20030712 & 4.6 & 13.98 & 85.47 & 8.73 & 1.59 & 550 \\
\hline 20031029 & 14.67 & 23.87 & 81.45 & 15.97 & 1.45 & 1100 \\
\hline 20031029 & 23.91 & 5.53 & 79.73 & 21.53 & 1.48 & 740 \\
\hline 20031120 & 17.88 & 4.48 & 83.88 & 27.49 & 1.96 & 790 \\
\hline 20031120 & 19.45 & 7.69 & 78.16 & 38.21 & 2.55 & 1280 \\
\hline 20040211 & 16.63 & 23.03 & 80.02 & 7.83 & 1.74 & 1090 \\
\hline 20040727 & 7.37 & 23.1 & 81.79 & 15.82 & 3.04 & 960 \\
\hline 20040727 & 15.12 & 23.21 & 82.08 & 21.72 & 2.79 & 300 \\
\hline 20040830 & 23.22 & 0.83 & 79.84 & 10.44 & 1.90 & 680 \\
\hline 20041108 & 6.02 & 14.5 & 83.72 & 20.68 & 1.29 & 490 \\
\hline 20041108 & 9.11 & 19.49 & 84.16 & 20.84 & 1.53 & 710 \\
\hline 20041109 & 21.83 & 13.37 & 83.56 & 20.91 & 2.32 & 1040 \\
\hline 20041110 & 8.76 & 0.89 & 79.76 & 17.86 & 2.23 & 520 \\
\hline 20050117 & 17.7 & 21.06 & 79.77 & 14.24 & 1.68 & 1060 \\
\hline 20050122 & 1.87 & 15.74 & 84.15 & 14.81 & 2.18 & 2270 \\
\hline 20050508 & 15.28 & 8.66 & 82.16 & 13.42 & 1.28 & 600 \\
\hline 20050515 & 10.82 & 12.13 & 84.32 & 17.41 & 1.93 & 980 \\
\hline 20050515 & 13.83 & 21.7 & 79.49 & 21.4 & 2.06 & 1450 \\
\hline 20050515 & 15.42 & 5.93 & 83.81 & 20.87 & 2.09 & 550 \\
\hline 20050531 & 1.38 & 5.78 & 85.21 & 11.56 & 1.54 & 1360 \\
\hline 20050612 & 19.17 & 3.04 & 79.04 & 15.19 & 2.53 & 2240 \\
\hline 20050613 & 2.82 & 7.2 & 78.91 & 15.59 & 1.95 & 820 \\
\hline 20050613 & 10.5 & 6.9 & 82.66 & 13.28 & 1.90 & 550 \\
\hline 20050824 & 12.23 & 19.62 & 79.39 & 19.54 & 1.95 & 1530 \\
\hline 20050824 & 16.76 & 17.35 & 85.61 & 21.61 & 1.73 & 980 \\
\hline 20050831 & 22.95 & 1.01 & 79.33 & 15.58 & 1.95 & 820 \\
\hline 20050911 & 13.97 & 20.09 & 79.5 & 12.83 & 1.51 & 600 \\
\hline 20050912 & 15.89 & 18.43 & 87.10 & 11.39 & 1.90 & 820 \\
\hline Average & & & & 15.70 & 1.88 & 928 \\
\hline Standard deviation & & & & 6.21 & 0.37 & 440 \\
\hline
\end{tabular}

the current sheet is assumed to be aligned with the auroral oval. FAC densities are calculated at a rate of $1 \mathrm{~Hz}$. This is equivalent to a spatial resolution of $7.6 \mathrm{~km}$.

\subsection{ACE data}

Interplanetary magnetic field (IMF) and solar wind data are taken from the Advanced Composition Explorer (ACE) spacecraft, which was launched on 25 August 1997. ACE is positioned near the L1 Lagrangian point approximately $220 R_{\mathrm{E}}$ in front of the Earth. We have used data from the Magnetic Field Experiment (MAG) (Smith et al., 1998) at $16 \mathrm{~s}$ resolution and the Solar Wind Electron, Proton, and Alpha Monitor SWEPAM (McComas et al., 1998) at $64 \mathrm{~s}$ resolution. MAG and SWEPAM data are re-sampled to one minute time resolution. Thereafter they are time shifted using the approach of phase front propagation technique (Weimer et al., 2003) to represent solar wind and IMF conditions at 
Table 1. Continued.

\begin{tabular}{|c|c|c|c|c|c|c|}
\hline $\begin{array}{c}\text { Date } \\
\text { (yyyymmdd) }\end{array}$ & $\begin{array}{l}\text { UT } \\
\text { (h) }\end{array}$ & $\begin{array}{l}\text { MLT } \\
\text { (h) }\end{array}$ & $\begin{array}{c}\text { Mlat } \\
\left({ }^{\circ}\right)\end{array}$ & $\begin{array}{c}\rho_{\text {peak }} \\
\left(10^{-12} \mathrm{~kg} / \mathrm{m}^{3}\right)\end{array}$ & $\begin{array}{c}\rho_{\text {rel }} \\
\left(^{\circ}\right)\end{array}$ & $\begin{array}{c}\text { FWHM } \\
(\mathrm{km})\end{array}$ \\
\hline \multicolumn{7}{|c|}{ Southern Hemisphere } \\
\hline 20020417 & 17.39 & 7.81 & -82.16 & 12.5 & 1.30 & 680 \\
\hline 20020419 & 10.96 & 9.24 & -80.61 & 13.96 & 3.88 & 680 \\
\hline 20021001 & 17.2 & 13.11 & -80.3 & 11.88 & 1.80 & 540 \\
\hline 20021001 & 18.67 & 23.31 & -78.18 & 9.03 & 1.81 & 740 \\
\hline 20030529 & 20.25 & 16.57 & -78.13 & 9.61 & 2.67 & 2080 \\
\hline 20040122 & 9.98 & 14.87 & -78.68 & 9.16 & 1.53 & 630 \\
\hline 20040211 & 18.87 & 10.32 & -86.67 & 8.87 & 1.64 & 1170 \\
\hline 20040725 & 14.83 & 6.16 & -88.5 & 7.71 & 1.93 & 540 \\
\hline 20040727 & 12.88 & 3.68 & -81.23 & 8.62 & 1.72 & 680 \\
\hline 20041110 & 3.27 & 23.36 & -80.01 & 26.44 & 2.94 & 1500 \\
\hline 20050117 & 13.82 & 10.9 & -81.75 & 17.49 & 3.50 & 1010 \\
\hline 20050508 & 12.93 & 20.94 & -88.32 & 10.82 & 2.16 & 830 \\
\hline 20050515 & 13.13 & 12.74 & -85.31 & 17.82 & 1.71 & 820 \\
\hline 20050530 & 7.82 & 3.88 & -78.15 & 7.67 & 1.78 & 770 \\
\hline 20050530 & 12.48 & 16.73 & -80.15 & 6.35 & 1.51 & 820 \\
\hline 20050612 & 22.92 & 19.17 & -88.5 & 6.92 & 1.38 & 900 \\
\hline 20050831 & 22.17 & 17.51 & -78.07 & 8.65 & 1.54 & 1370 \\
\hline 20050911 & 2.57 & 4.07 & -84.77 & 11.23 & 2.04 & 490 \\
\hline 20050913 & 0.42 & 11.10 & -78.28 & 12.54 & 1.31 & 580 \\
\hline Average & & & & 11.44 & 2.01 & 886 \\
\hline Standard deviation & & & & 4.85 & 0.73 & 399 \\
\hline
\end{tabular}

the front side magnetopause, which is assumed to be located at a distance of $10 R_{\mathrm{E}}$ at the sub-solar point. The transit time to the magnetopause of each event was computed individually using the actual solar wind speed data. An additional average delay of $15 \mathrm{~min}$ has been considered for the thermospheric response to solar wind input at the magnetopause.

\subsection{DMSP data}

The Defense Meteorological Satellites Program (DMSP) has launched a series of spacecraft to investigate among others the ionospheric plasma at about $840 \mathrm{~km}$ altitude. They were all put into Sun-synchronous orbits (inclination $\sim 97$ degrees). In this study data from DMSP F13 have been used (http://cindispace.utdallas.edu/DMSP/dmsp_data_ at_utdallas.html). F13 is roughly in a dawn-dusk orbit. The data considered here is the $V_{\mathrm{z}}$ component of the plasma bulk flow at $4 \mathrm{~s}$ resolution.

\section{Observations}

In this study, we focus on the mass density anomalies in the polar cap occurring during geomagnetic storms. For the definition of a storm we made use of the storm time index, Dst. All disturbed periods reaching Dst $<-100 \mathrm{nT}$ were classified as major magnetic storms. A similar threshold for major storms is used also by Zhang et al. (2007). In their Table 1 detailed characteristics of all the major storms from 1996 to 2005 are listed. During the 4 years considered here (20022005) 29 such storm events occurred. Before starting a statistical analysis of all storms we will present four events in detail pointing out the features that may be of interest for the interpretation.

\subsection{The storm of 17-19 January 2005}

This event is special since it exhibits density anomalies both in the northern and southern polar cap. The variations of the Dst index, interplanetary magnetic field (IMF) components $B_{\mathrm{y}}$ and $B_{\mathrm{z}}$ in GSM (Geocentric-Solar-Magnetospheric) coordinates, solar wind velocity and solar wind dynamic pressure during the geomagnetic storm of 17-19 January 2005 are presented in Fig. 1 from top to bottom. They are plotted as functions of universal time (UT), which starts from 17 January 2005, 00:00 UT.

From the solar wind data we can deduce that the storm lasted for almost $40 \mathrm{~h}$. Interestingly, the Dst index attained only moderate values, hardly going below $-100 \mathrm{nT}$. The IMF, however, became strong (>20 nT) and the components vary rapidly between positive and negative values. Particularly large solar wind speeds, surpassing $1000 \mathrm{~km} / \mathrm{s}$, are observed. The dynamic pressure is a derived quantity, therefore also here a gap shows up where the solar wind data are 

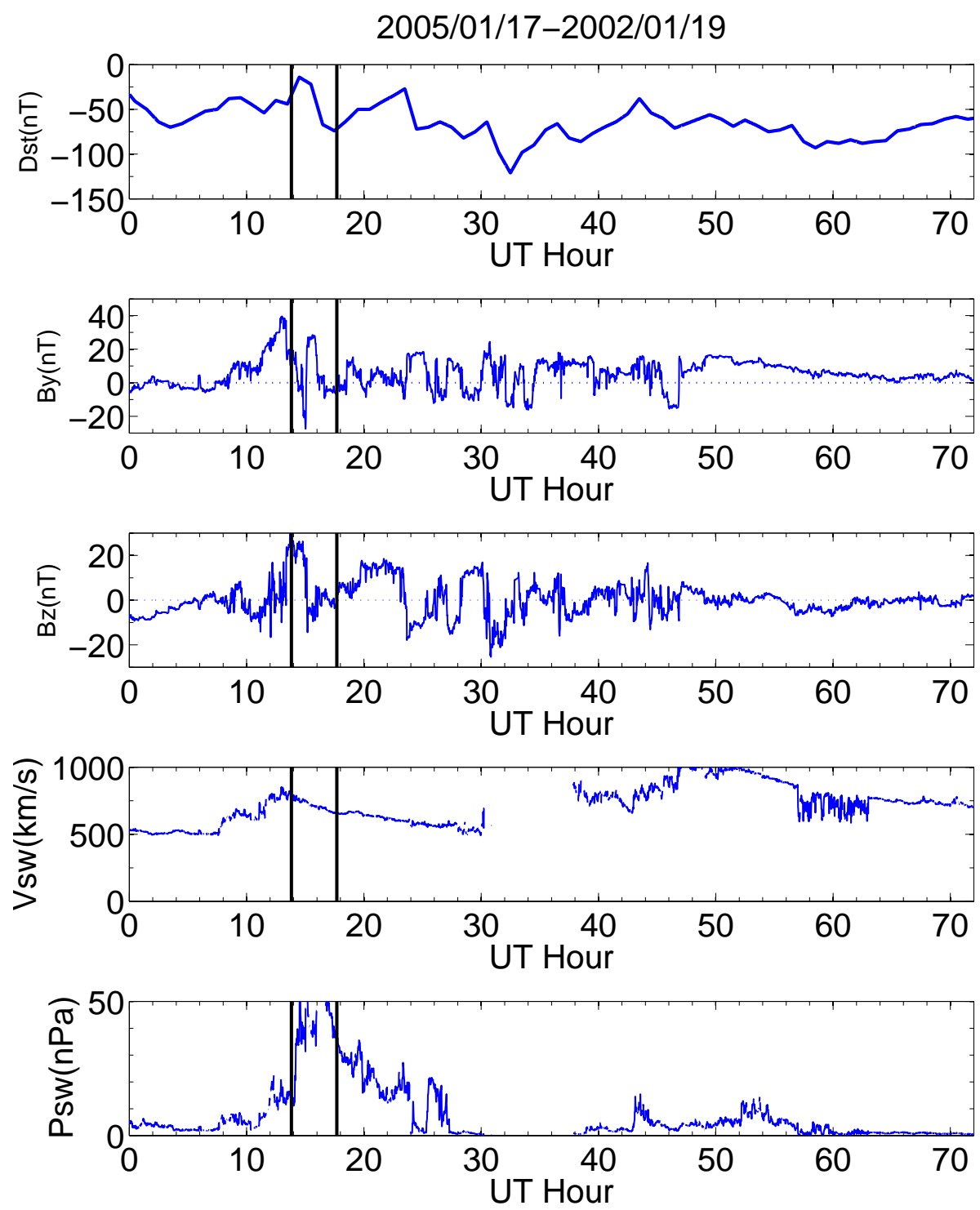

Fig. 1. Geophysical conditions during 17-19 January 2005. From top to bottom are Dst index, IMF $B_{\mathrm{y}}, B_{\mathrm{Z}}$, solar wind velocity and dynamic pressure plotted as functions of UT time. The vertical solid lines mark the times of the thermospheric density anomalies in the polar cap.

missing. An outstanding feature is the high pressure. The pressure rose to $16 \mathrm{nPa}$ shortly after 12:00 UT and jumped up again to $50 \mathrm{nPa}$ around 14:00 UT. The two vertical lines mark the times of the thermospheric density anomalies in the polar cap. During the days 17 to 19 January 2005 the corresponding F10.7 solar flux index, as the proxy of solar EUV radiation, was 133, 120 and 128, respectively.

The thermospheric mass density inferred by CHAMP during this storm is shown in Fig. 2. Data from each CHAMP orbit are divided in the descending and the ascending part. Therefore the top panel shows the descending half and the bottom panel the ascending half. In the following they are referred to as the evening and the morning side recordings, respectively, according to the equatorial magnetic local times (MLT) given in the header of each panel. For the presentation inter-orbit interpolation is performed to derive the 2dimensional colored distribution, which is apparently continuous both in time and geomagnetic latitude. One has to keep in mind that the actual satellite measurements are only confined to individual orbit tracks.

Pronounced mass density enhancements are detected during the magnetic activity. On the evening side, the densities begin to rise shortly before 12:00 UT, first at higher southern latitudes, and about four hours later it shows up in the Northern Hemisphere. In both panels of Fig. 2 large scale traveling atmospheric disturbances (TADs) can be found, especially 

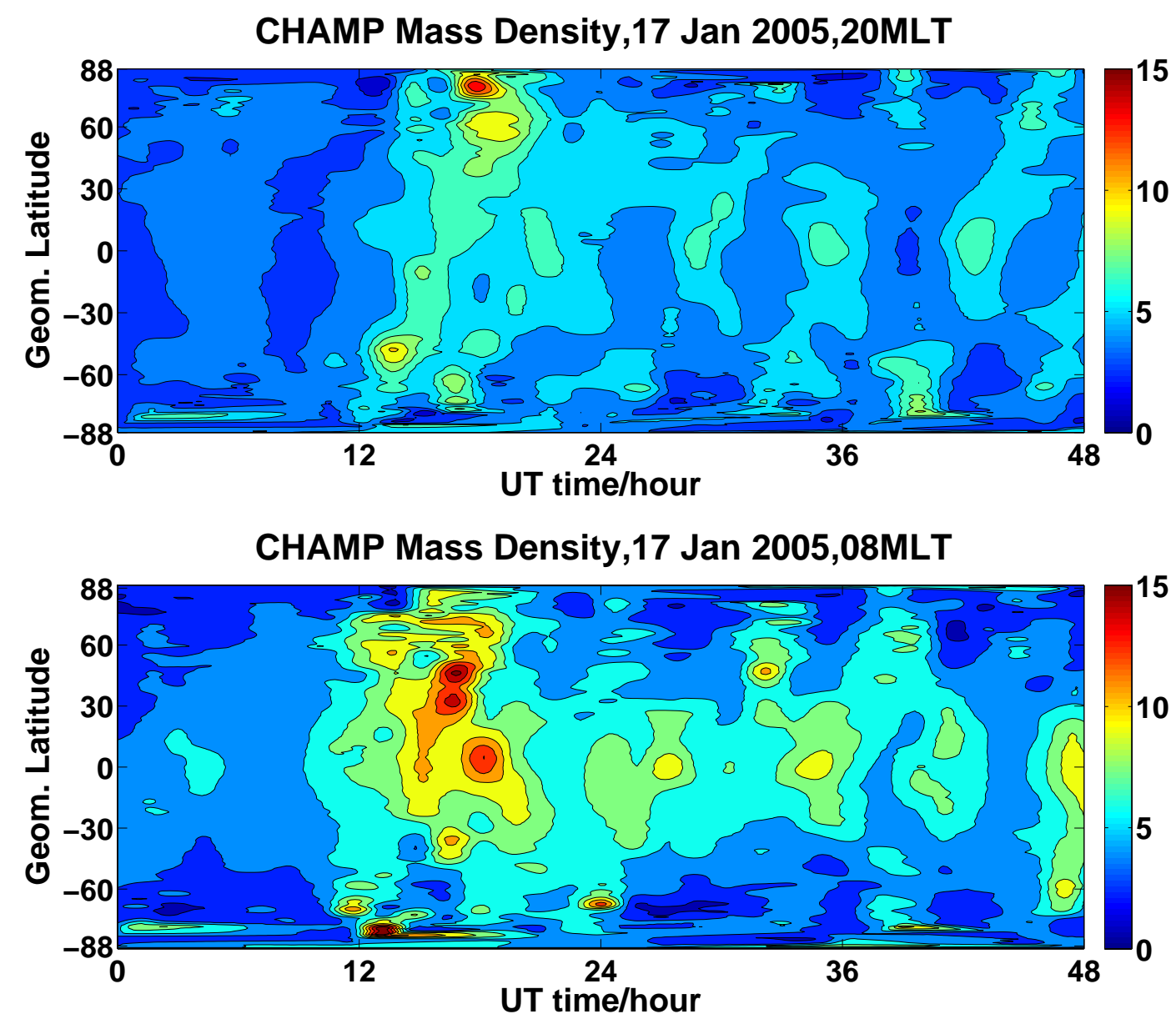

Fig. 2. The thermospheric density (in units of $10^{-12} \mathrm{~kg} / \mathrm{m}^{3}$ ) inferred from CHAMP accelerometer data, versus geomagnetic latitude and time, during the 17-19 January 2005. The top panel shows the density on the evening side (20:00 MLT) and the bottom on the morning side (08:00 MLT).

in summer hemisphere. They are typically separated by $6-$ $7 \mathrm{~h}$, which fits reasonably well the major southward turnings of the IMF (see Fig. 1). The propagation speed is around $700 \mathrm{~m} / \mathrm{s}$, which is consistent with the results of Bruinsma and Forbes (2007).

The investigation of the local time dependent global response of the thermosphere to geomagnetic storms is definitely an attractive problem, but in this study we will focus on the density anomalies in the polar cap region. In Fig. 2 there appear two isolated high density features at polar cap latitudes, at 13:50 UT in the Southern Hemisphere (lower panel) and 17:42 UT in the Northern Hemisphere (upper panel). There are no other prominent features detected poleward of $75^{\circ}$ magnetic latitude (black lines in Fig. 2) during that storm.

The density anomalies in the polar caps of both hemispheres are replotted in Fig. 3, along with the field-aligned current (FAC), electron density and electron temperature, as measured by CHAMP. The quantities are plotted versus geo- magnetic latitude of the CHAMP orbit. The gap near the geomagnetic pole represents the region not sampled by CHAMP.

Figure 3a shows in the top panel the density anomaly in the Southern Hemisphere along with the other parameters. CHAMP is approaching from the night side. At around 11 magnetic local time (MLT) (see figure heading) it passes the anomaly. In this region the mass density has almost tripled compared to the background. The FACs are moderate on the night side, but they increase dramatically when CHAMP passes the density anomaly. The electron density and temperature are enhanced simultaneously as well. This coincidence of the density anomaly with strong FACs and high temperatures suggests Joule heating as the cause of the air upwelling.

In the same format as before, Fig. $3 \mathrm{~b}$ shows the CHAMP observations in the vicinity of the density anomaly in the northern polar cap. The satellite coming from the morning side passes through the noon sector to the evening side. The secondary maximum in density, just beyond $70^{\circ}$, marks the cusp anomaly (Rentz and Lühr, 2008). Around 16:00 MLT 

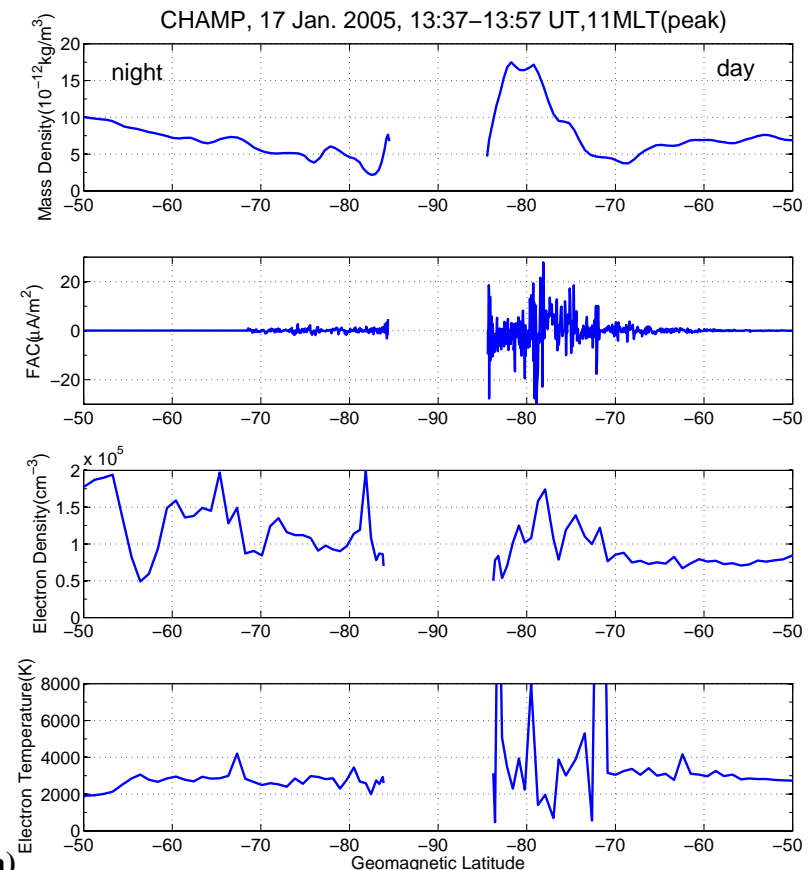

(a)
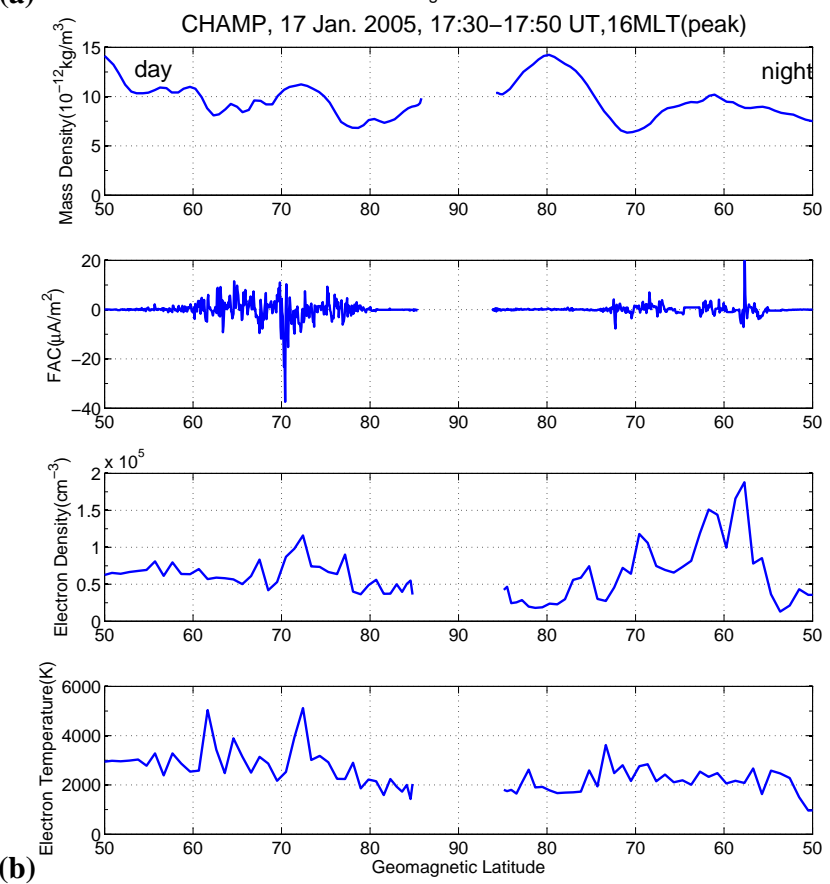

Fig. 3. The density anomalies on 17 January 2005 in the southern (a) and northern (b) polar cap. The $\mathrm{x}$-axis of the diagram indicates the geomagnetic latitude of the CHAMP observations. The gaps near the geomagnetic poles mark the regions not sampled by CHAMP. The magnetic local times shown in the headings are for the density peaks.

CHAMP passes the polar cap anomaly. Here the density is enhanced about 1.8 times above the ambient. The panel below indicates intense FAC activity within the dayside auroral
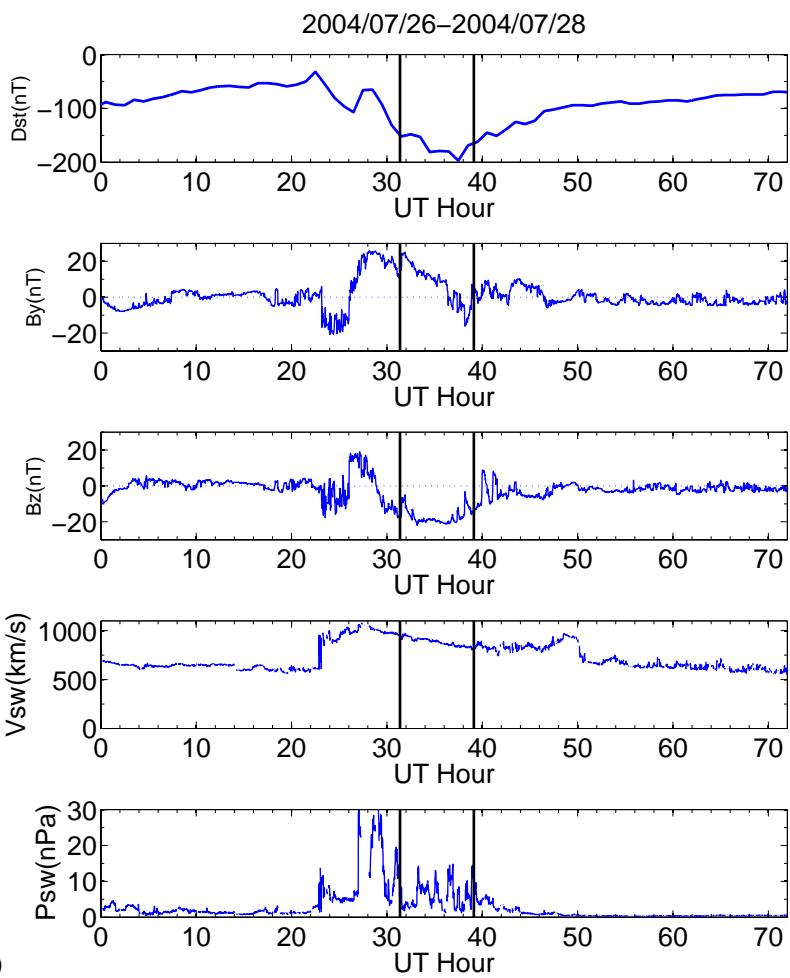

(a)
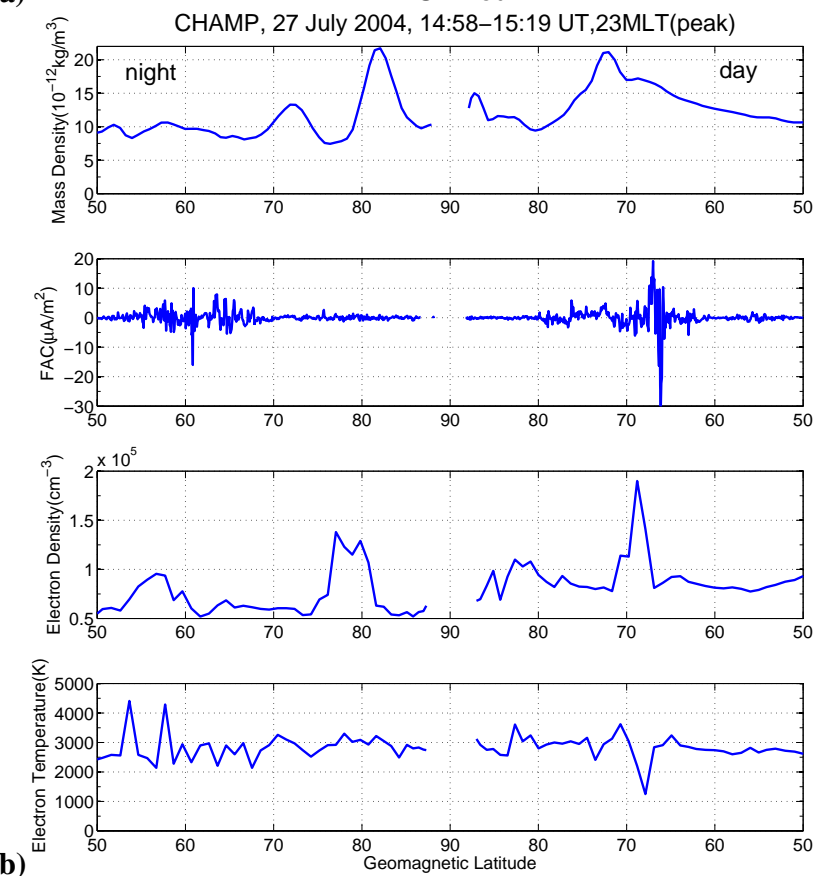

Fig. 4. Comparison of geophysical conditions during the storm on 26-28 July 2004 with the ionospheric/thermospheric response at the time of the polar cap density anomaly. Panel (a) shows the Dst index, IMF $B_{\mathrm{y}}$ and $B_{\mathrm{Z}}$ components, solar wind speed and dynamic pressure. Panel (b) shows the thermospheric density anomaly, along with FAC, electron density and temperature as observed along the CHAMP track. 

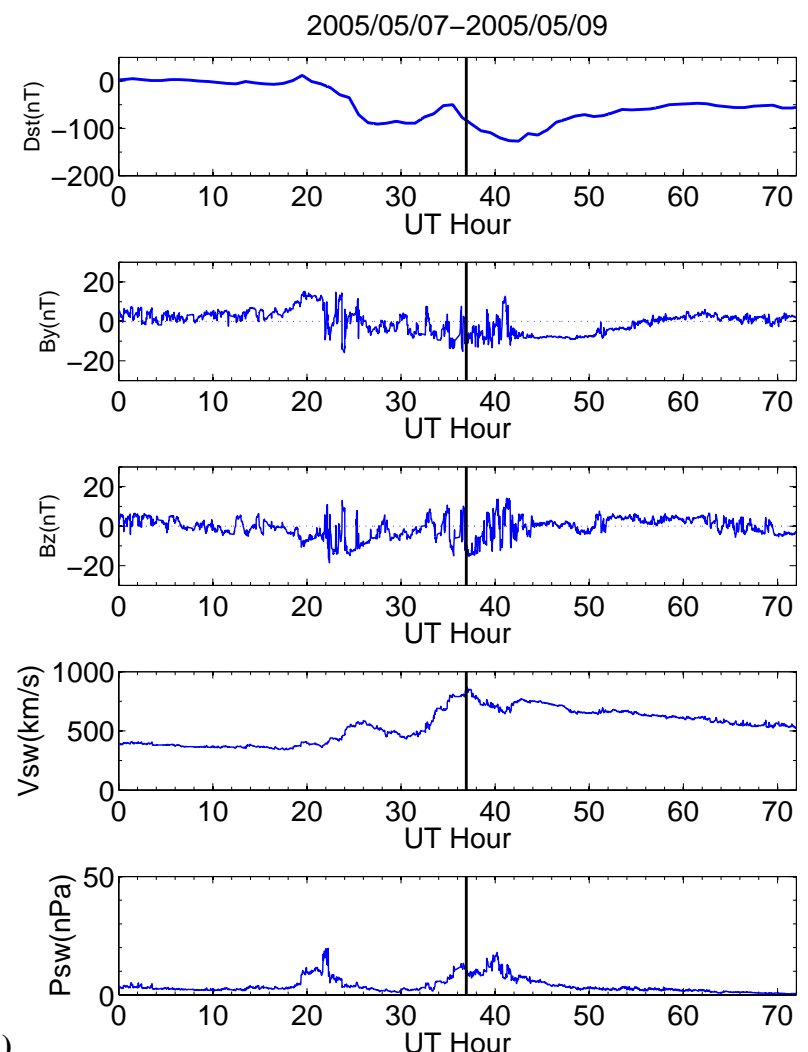

(a)
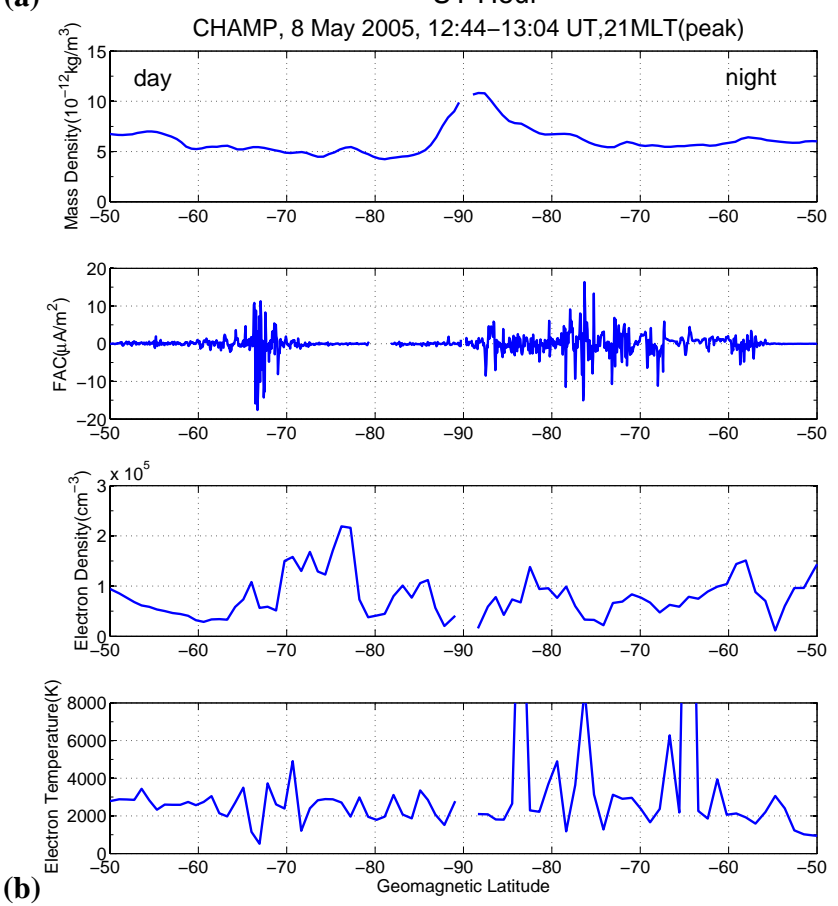

Fig. 5. Same format as Fig. 4, but for the storm on 8 May 2005.

region and in particular at cusp latitudes. Some weaker FACs are observed in the late evening auroral region. Interestingly, there is a total void of FACs at the location of the polar
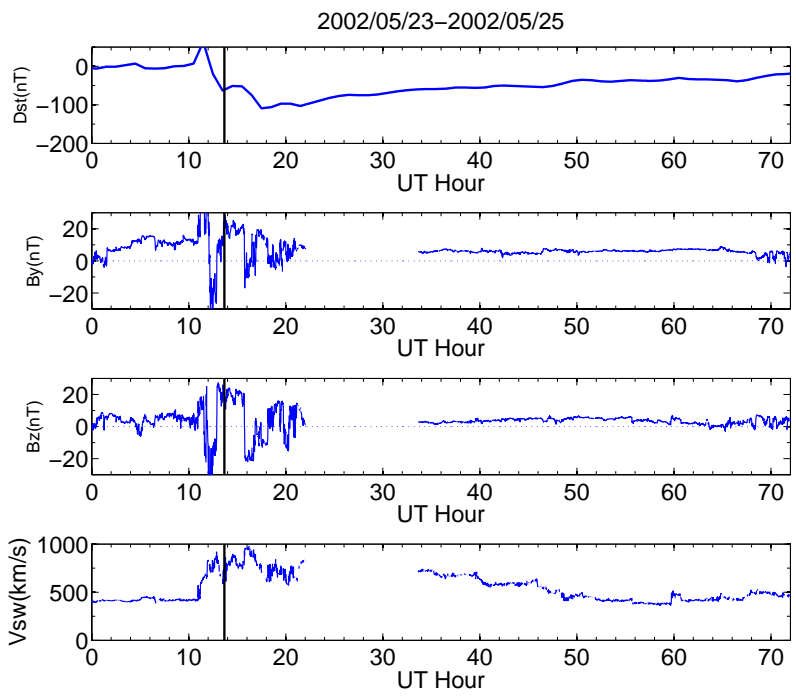

(a)
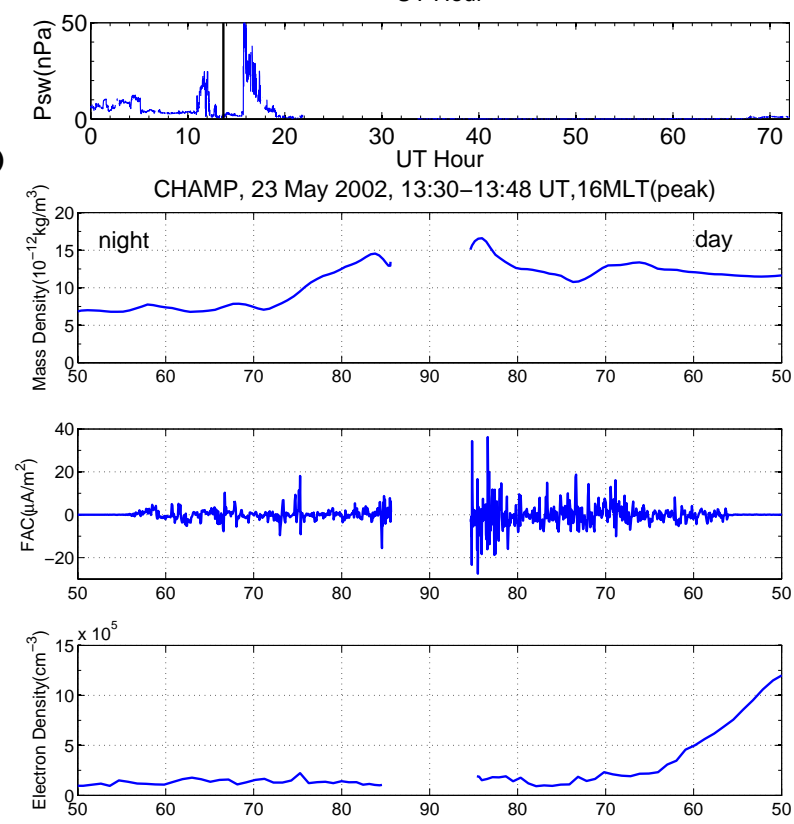

(b)

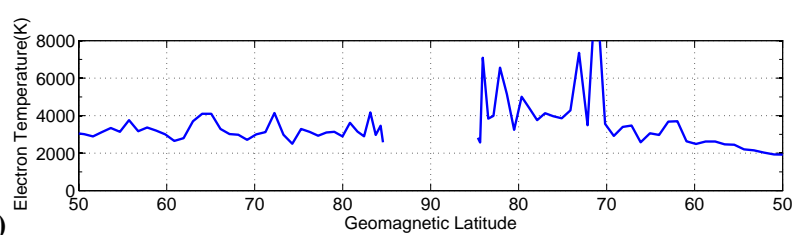

Fig. 6. Same format as Fig. 4, but for the storm on 23 May 2002.

cap anomaly. Similarly, the electron density and temperature are low at the latitude of the mass density peak, whereas they show some correlation to the FAC activity. This density anomaly event obviously requires quite a different explanation than that previously shown.

In this context we may check the interplanetary conditions during the two events, as shown in Fig. 1. The anomaly in the southern polar cap coincided with strongly positive $(\sim 20 \mathrm{nT})$ IMF $B_{\mathrm{y}}$ and $B_{\mathrm{z}}$ components and with a largely enhanced 
dynamic pressure. During the Northern Hemisphere event the dynamic pressure is even higher, while the IMF $B_{\mathrm{y}}$ and $B_{\mathrm{Z}}$ components varied around zero. An attempt to explain the difference will be offered in Sect. 5 .

\subsection{The storm of 26-28 July 2004}

A large anomaly in the northern polar cap is found during the storm of 26-28 July 2004. Figure 4a presents the prevailing geophysical conditions. The storm started shortly after 22:00 UT on 26 July 2004 with a pronounced sudden storm commencement (SSC). Subsequently the Dst decreased, reaching $-200 \mathrm{nT}$ at the end of the main phase $15 \mathrm{~h}$ later. The IMF is strong with magnitudes exceeding $30 \mathrm{nT}$. The components $B_{\mathrm{y}}$ and $B_{\mathrm{z}}$ exhibit bipolar variations suggesting the passage of a solar flux rope. Solar wind speeds up to $1000 \mathrm{~km} / \mathrm{s}$ are reached. Consequently, the dynamic pressure is enhanced. The occurrence of two polar cap anomalies is marked by vertical lines. Both are accompanied by strongly negative IMF $B_{Z}$ and fluctuating dynamic pressure around $5 \mathrm{nPa}$.

Figure $4 \mathrm{~b}$ presents the CHAMP observations associated with the later and more prominent polar cap event. The satellite comes from the night side, detects the major density anomaly poleward of $80^{\circ}$ Mlat around midnight and subsequently encounters the cusp anomaly at $73^{\circ}$ Mlat. Intense FAC activity is observed within the auroral regions on the night- and dayside. At the latitude of the polar cap anomaly no significant FACs are present. In this case we find electron density peaks close to the polar cap and cusp density anomalies. No particular signatures are observed in the electron temperature in connection with the anomalies. The earlier polar cap event (not shown here) occurred also in the Northern Hemisphere. About $9 \mathrm{~h}$ after the SSC a rather broad mass density maximum is observed at $83^{\circ}$ Mlat close to midnight. Concurrent with the event intense FACs are detected at auroral latitudes on the day and night side. Here again the FAC activity is confined to a small latitudinal range on the dayside, while spanning a wide range from $55^{\circ}$ to beyond $80^{\circ}$ Mlat on the night side. The role of the FACs for the anomaly can therefore not clearly be decided. There are no peaks in electron density and temperature concurrent with the mass density.

\subsection{The storm of 8 May 2005}

Observations associated with a mass density anomaly occurring at the southern geomagnetic pole on 8 May 2005 are shown in Fig. 5. Prevailing conditions during this storm are presented in Fig. 5a. The event time is marked again by a vertical line. The IMF $B_{\mathrm{y}}$ and $B_{\mathrm{z}}$ components switched from positive to negative about $2 \mathrm{~h}$ prior to the event. The solar wind speed has attained its peak value and the dynamic pressure is high, exceeding $10 \mathrm{nPa}$.

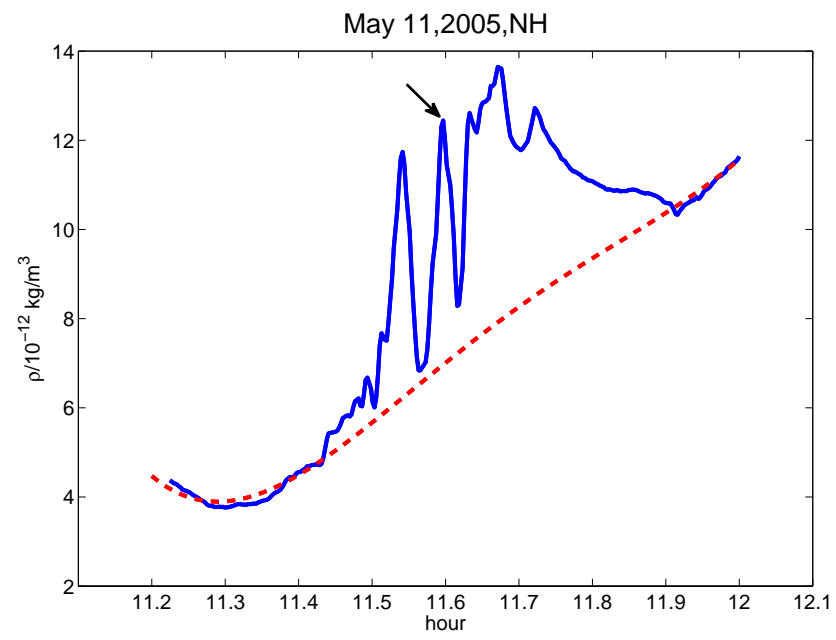

Fig. 7. One example of the background density derived by visual inspection. The blue solid line denotes the density along one CHAMP orbit, the red dashed line denotes the background density. The black arrow marks one density anomaly within northern polar cap on 11 May 2005.

The CHAMP observations in Fig. 5b show a nicely isolated density anomaly right at the southern geomagnetic pole. In the panel below, the FACs on the dayside are well confined to the cusp latitude, but there is no associated density anomaly. On the night side intense FACs are observed throughout the auroral latitudes reaching poleward deep into the polar cap. There may be a connection with the anomaly. Electron temperatures are enhanced, in particular, on the night side in regions of strong FACs. None of the plotted parameters show a specific feature confined to the density anomaly.

\subsection{The storm of 23 May 2002}

A prominent and large scale density anomaly in the northern polar cap is found during the storm of 23-25 May 2002. The prevailing geophysical conditions are presented in Fig. 6a. The anomaly event is again marked by a vertical solid line. The geomagnetic storm started shortly after 11:00 UT on 23 May 2005 with a pronounced SSC. The Dst index declined shortly thereafter, reaching its minimum at around 17:00 UT at a value of $-110 \mathrm{nT}$. At the event time the IMF components $B_{\mathrm{y}}$ and $B_{\mathrm{z}}$ both attained strong positive values around $20 \mathrm{nT}$. These IMF conditions are quite similar to the ones prevailing during the earlier event, as shown in Fig. 1. The solar wind speed is also high, reaching $800 \mathrm{~km} / \mathrm{s}$. The dynamic pressure is, however, moderate during the event, below $5 \mathrm{nPa}$.

Figure $6 \mathrm{~b}$ presents the CHAMP observations associated with the isolated polar cap event. The satellite comes from the nightside, detecting the density anomaly poleward of $84^{\circ}$ Mlat at 16:00 MLT. Strongly enhanced FACs are observed 

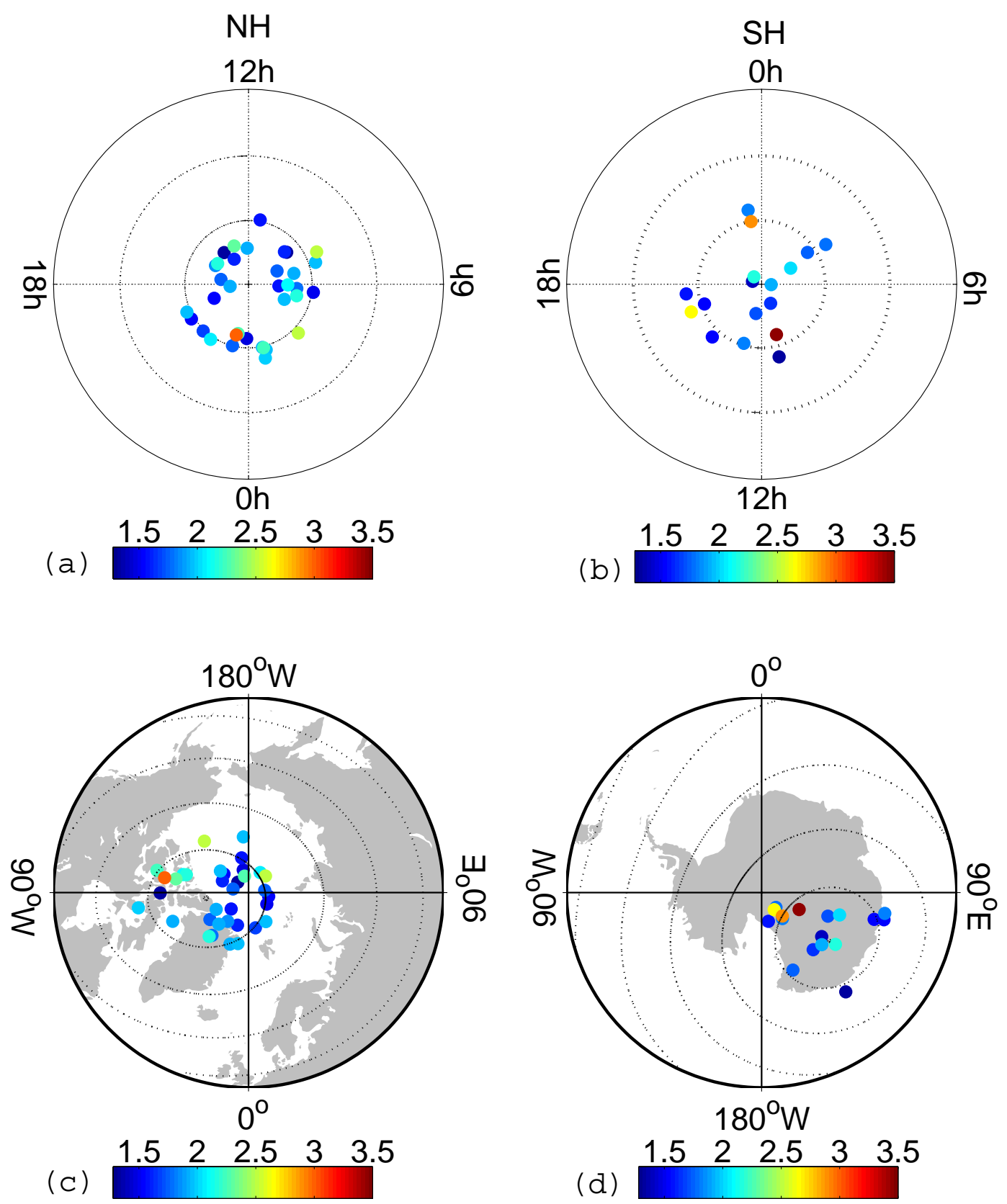

Fig. 8. Location and relative density amplitude of the anomaly peaks in geomagnetic coordinates (a, b) and geographic coordinates (c, d) in both hemisphere. Geomagnetic latitude circles are drawn at $10^{\circ}$ spacing.

throughout the high latitudes, especially at latitudes of the anomaly peak, where the electron temperature is also high. With these features the CHAMP observations are quite similar to the ones shown in Fig. 3a.

\section{Statistical study}

In this section we intend to present some statistical characteristics of the detected mass density anomalies in the polar cap region. We make use of CHAMP data during 2002 to 2005 . Within those 4 years we considered 29 magnetic storms which exhibited Dst $<-100 \mathrm{nT}$. In 26 storms (90\%) we found density anomalies. The remaining 3 storms were rather weak, hardly exceeding Dst $=-100 \mathrm{nT}$. If the 


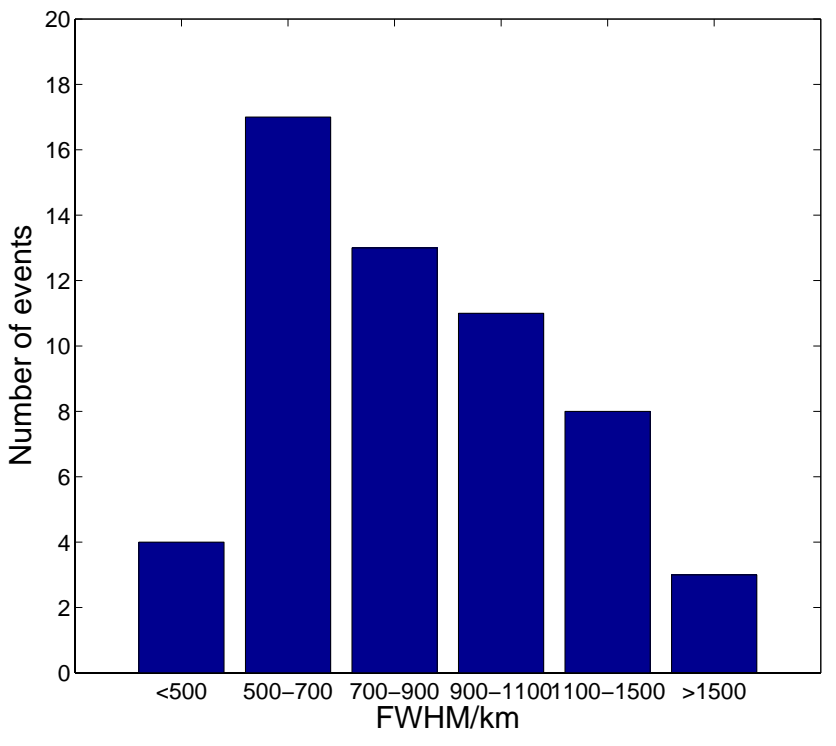

Fig. 9. Latitudinal width at half-maximum of the polar cap mass density anomalies.

maximum of density enhancement reached at least $120 \%$ of the prevailing background value, and if it was detected poleward of $\left|78^{\circ}\right|$ Mlat by CHAMP, then it is regarded an anomaly event in the polar cap region. Geomagnetic rather than geographic latitudes are used for the description because we are interested in storm-related effects.

Altogether 56 density anomalies are found within the polar caps. Table 1 lists their peak amplitude and relative amplitude, along with date, universal time (UT) and magnetic local time (MLT), geomagnetic latitude and the full width at half maximum (FWHM) separately for the Northern and Southern Hemispheres. Relative density, $\rho_{\text {rel }}$, is calculated as:

$\rho_{\text {rel }}=\frac{\rho}{\rho_{\mathrm{amb}}}$

where $\rho$ is the mass density peak and $\rho_{\text {amb }}$ is the corresponding background density. The background density is determined by visual inspection. This means we draw a line connecting the background densities before and after the anomaly. For our study we consider this approach to derive background information more appropriate than taking running mean or using quiet-day level. Figure 7 presents an example how the background densities is derived by visual inspection.

Table 1 indicates that $29 \%$ of the density peaks have a relative density larger than 2 , while $59 \%$ of them are between $1.5-2$, and the rest is below 1.5. This indicates that we are dealing with major enhancements.

When looking at the peak amplitudes separately for the two hemispheres we find on average $15.70 \times 10^{-12} \mathrm{~kg} / \mathrm{m}^{3}$ and $11.44 \times 10^{-12} \mathrm{~kg} / \mathrm{m}^{3}$ for the Northern and Southern Hemisphere, respectively. The standard deviation amounts in both cases to about $40 \%$. From the observed amplitudes we see that the anomalies are larger by about $37 \%$ in the north than in the south. However, the relative density in Northern Hemisphere is 7\% smaller than in the southern. This is an indication for the role the ambient density plays for the anomaly peak.

The location in geomagnetic coordinates and the relative amplitude of the density anomalies are plotted in Fig. 8a, b. The coordinate frame we are using is the apex coordinate system Richmond (1995). The dashed circles in each panel denote geomagnetic latitudes at $10^{\circ}$ spacing, starting from $\pm 80^{\circ}$ Mlat at the innermost circle. It can be seen that in the Northern Hemisphere the anomalies occurred not only more frequently (37 events compared to 19 events in the Southern Hemisphere), but the amplitudes are also larger.

Figure 8c, d shows the relative anomaly peaks in both hemispheres now in geographic coordinates. In this frame a possible influence of the solar zenith angle (SZA) with its dependence on latitude can be considered. The SZA is a measure for the amount of solar illumination, which influences directly the conductivity of the ionosphere and the thermosphere density. There is no evidence from the two dial plots that the sunlight has direct effects on the occurrence and amplitude of density anomalies in the polar cap region.

Another characteristic quantity is the horizontal scale size of the anomaly. Figure 9 shows the distribution of full width half maximum (FWHM) as listed in Table 1. Highest count $(30 \%)$ is found in the range $500 \mathrm{~km}-700 \mathrm{~km}$. The occurrence of events decreases towards larger scales. Beyond $1500 \mathrm{~km}$ and below $500 \mathrm{~km}$ it can be regarded as negligible. With typical scale sizes of $900 \pm 400 \mathrm{~km}$ we may classify them as medium-scale phenomenon.

Since the polar cap anomalies only occur during magnetic storms, the dependences on storm-related parameters should also be investigated in a statistical way. First let us take a look at the storm phase, during which an event occurs. Out of 56 events 23 anomalies are observed during the main phase of the storms, 28 of the events are observed during the recovery phase, while only 5 events are observed at the initial phase or SSC of the storms. This indicates that the anomalies require a few hours for forming.

In the next step the dependence on IMF orientation is investigated. We divide IMF $B_{\mathrm{y}}$ and $B_{\mathrm{z}}$ into 3 different ranges, respectively, negative, zero, positive. Then we sorted the 56 density peaks into the $3 \times 3$ subsets. Since $B_{\mathrm{Z}}$ has symmetric effects in both hemispheres, while $B_{\mathrm{y}}$ is expected to have opposite effects in both hemispheres, all the density events are sorted according to northern hemispheric conditions. This means, we have used for all peaks in the Southern Hemisphere an opposite sign for $B_{\mathrm{y}}$. Figure 10 shows the location and relative amplitude of the density anomaly peaks with respect to the 9 subsets. From the left column to the right $B_{\mathrm{y}}$ is classified by $B_{\mathrm{y}}<-3 \mathrm{nT},-3 \mathrm{nT}<B_{\mathrm{y}}<3 \mathrm{nT}, B_{\mathrm{y}}>3 \mathrm{nT}$, while $B_{\mathrm{Z}}$ is classified from the bottom row to the top by $B_{\mathrm{Z}}<-5 \mathrm{nT},-5 \mathrm{nT}<B_{\mathrm{Z}}<5 \mathrm{nT}, B_{\mathrm{Z}}>5 \mathrm{nT}$. The threshold 

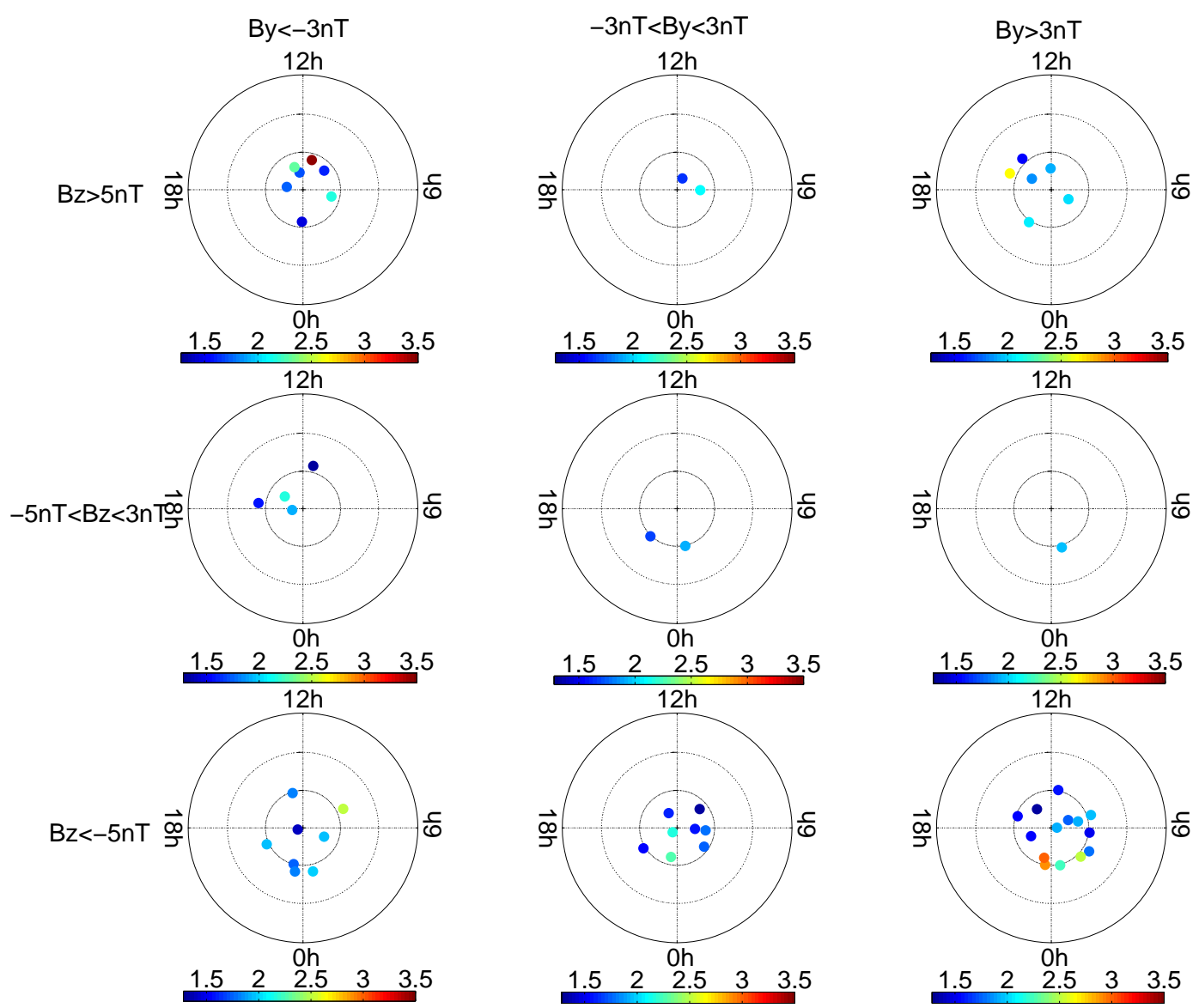

Fig. 10. The location and relative density amplitude of the anomaly peaks in different IMF $B_{\mathrm{y}}$ and $B_{\mathrm{Z}}$ ranges in geomagnetic coordinates. The peaks are normalized to Northern Hemisphere conditions. From left to right the ranges of $B_{\mathrm{y}}$ are: $B_{\mathrm{y}}<-3 \mathrm{nT},-3 \mathrm{nT}<B_{\mathrm{y}}<3 \mathrm{nT}$, $B_{\mathrm{y}}>3 \mathrm{nT}$; from bottom to top the ranges for $B_{\mathrm{Z}}$ are: $B_{\mathrm{Z}}<-5 \mathrm{nT},-5 \mathrm{nT}<B_{\mathrm{Z}}<5 \mathrm{nT}, B_{\mathrm{Z}}>5 \mathrm{nT}$.

values have been chosen in order to obtain a reasonable distribution of events. There are several things to notice. First, few anomalies occurred for small $B_{\mathrm{y}}$ or $B_{\mathrm{z}}$, except when $B_{\mathrm{z}}$ is negative. Second, anomalies occurred more frequently under positive $B_{\mathrm{z}}$ when $B_{\mathrm{y}}$ had a substantial amplitude. Third, the distributions show no clear local time dependence.

Since the occurrence of density anomalies has a strong dependence on the orientation of $B_{\mathrm{Z}}$, we investigate the relationship between $B_{\mathrm{Z}}$ orientation and FAC intensity. In many cases the FAC density varies rapidly between strongly positive and negative values. We calculated therefore the root mean square (RMS) values of FAC density within the full width at half maximum (FWHM) of the density anomalies and regarded them as the representative values of FAC intensity for each anomaly. Figure 11 shows the obtained FAC intensity for each density anomaly versus IMF $B_{z}$. The dotted vertical line marks FAC density $=0.5 \mu \mathrm{A} / \mathrm{m}^{2}$. These small intensities are regarded as quiet time value of the small-scale FACs (e.g. Rother et al., 2007). Pronounced FACs can be found for both positive and negative $B_{\mathrm{Z}}$. About half of the
FACs have a value less than $0.5 \mu \mathrm{A} / \mathrm{m}^{2}$. For the remaining events the figure implies that strong FACs tend to appear where $B_{\mathrm{Z}}$ is also strong, and the rate of increase for strong FACs is almost equal for positive and negative $B_{\mathrm{Z}}$.

\section{Discussion}

To our knowledge very few studies have been carried out on thermospheric density anomalies in the polar cap region during geomagnetic storm time. Here we make use of CHAMP accelerometer measurements covering the four years 2002 to 2005 during the declining phase of the solar cycle. Prime purpose of this paper is the presentation of the observed characteristics of the anomalies.

\subsection{Relation of the density anomaly with magnetic storm}

We regard the polar cap anomalies as a magnetic storm related phenomena. This is concluded from the study of Rentz 


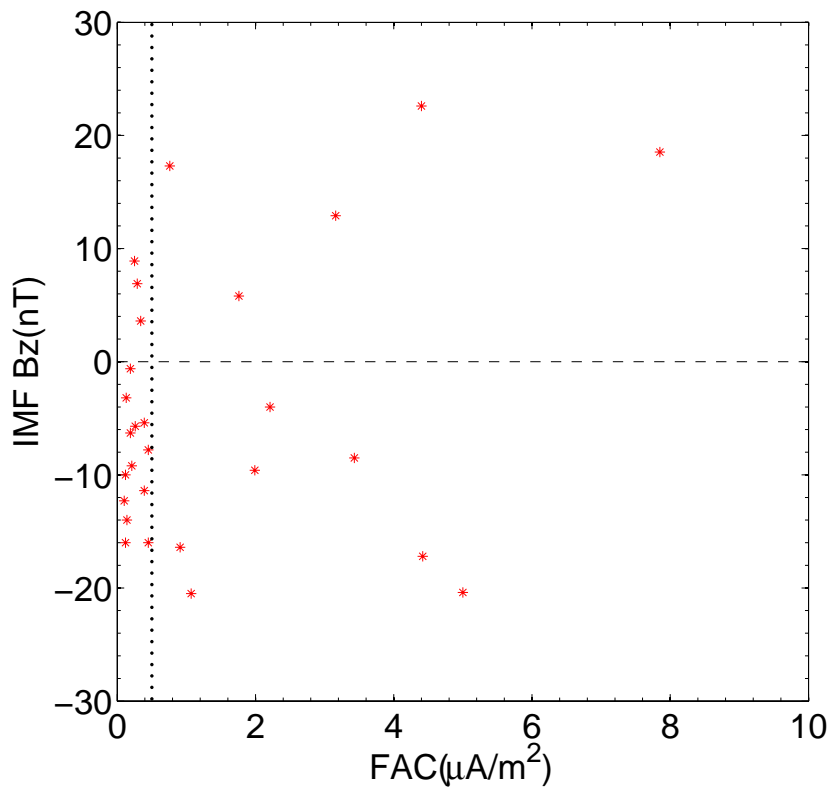

Fig. 11. RMS values of FAC intensity for each density anomaly as function of $B_{\mathrm{Z}}$. The dotted vertical line marks FAC density $=0.5 \mu \mathrm{A} / \mathrm{m}^{2}$, which is regarded as quiet-time limit.

and Lühr (2008) who investigated polar cusp related mass density anomalies making use of the same CHAMP ACC data set. They restricted their analysis to periods with $\mathrm{Kp} \leq 4$. From their Fig. 10 one can see that there is a blank area at polar cap latitudes void of density anomalies. Our Fig. 8 can thus be seen as an extension to high activity. In $90 \%$ of the occurring storms we detected density anomalies with enhancement factors larger than $120 \%$.

According to our observations, the same anomaly was in general only detected within one CHAMP orbit. Detections of anomalies in successive orbits are rare and are not considered to be related. Therefore it may be concluded that their dwell-time within the polar cap is less than $1.5 \mathrm{~h}$. This, however, implies that we may have missed a number of them. Therefore, density peaks in the polar cap seem to be a typical storm-time phenomenon. With regard to the storm phase the polar cap anomalies tend to prefer later storm phases, as mentioned in Sect. 4. This suggests that the conditions for the anomalies to occur in the polar cap require some time for setting up.

\subsection{Characteristics of the anomalies}

Important features of polar cap anomalies are listed in Table 1. The parameters have been sorted by hemisphere. It is obvious that many more events were found in the Northern Hemisphere. Also the measured peak density is clearly larger there. Both features higher occurrence rate and larger amplitude in the Northern Hemisphere were also reported by Rentz

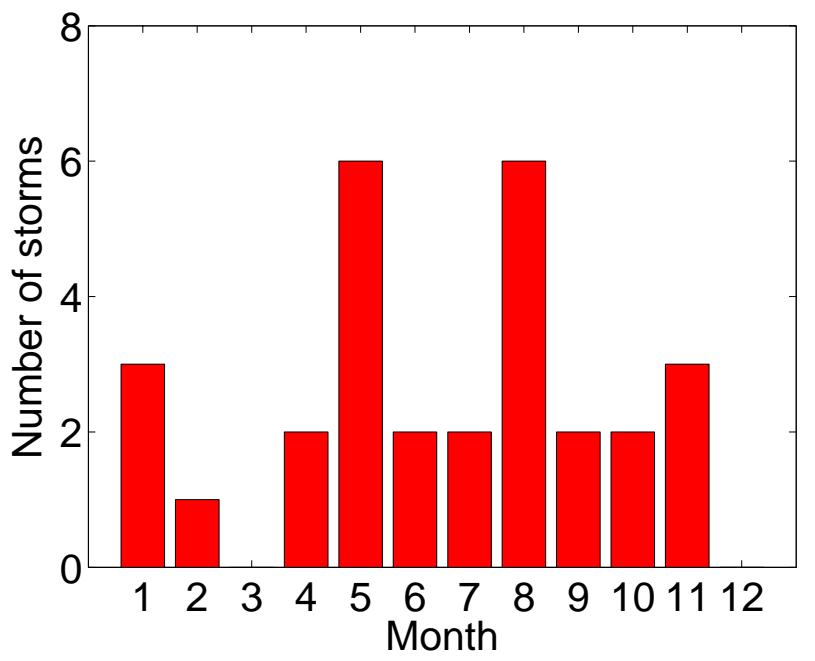

Fig. 12. Occurrence distribution of magnetic storms during 2002 2005.

and Lühr (2008) for the cusp density anomalies. The thermospheric density is strongly dependent on several parameters such as altitude, solar flux or season. During the considered 4 years the CHAMP altitude decayed from $425 \mathrm{~km}$ to $360 \mathrm{~km}$ which corresponds to approximately one scale height. The yearly-averaged solar flux F10.7 declined from 179 in 2002 to 92 in 2005.

In order to check for a possible influence of the background density on the size of the anomaly we calculated also the relative enhancement. A value of $\rho_{\text {rel }}=1.2$ had been chosen as the threshold for an anomaly. When we compare the numbers between the two hemispheres, we notice that, although the peak density in the north is on average 37\% larger than that in the southern, the average of relative amplitudes is well balanced between the hemispheres. This implies that the differences in ambient thermospheric density may play a role in the preference of the Northern Hemisphere for the formation of anomalies. In order to check that assumption we have a look at the seasonal distribution of the events. As can be derived from Table 1, about half of the anomalies were detected during the months around June solstice (MayAugust). The rest equally distributed between December solstice (November-February) and equinox (March, April, September, October). This partitioning is approximately the same for both hemispheres, and it reflect the seasonal distribution of the considered storms, as shown in Fig. 12. This somewhat surprising result, the missing seasonal difference between the hemispheres, suggests that the solar insulation has no influence on the formation of anomaly. Also the ambient Thermospheric density does not seem to have a significant influence. It had earlier been shown by Liu et al. (2007) that the thermospheric density is severely reduced in the Southern Hemisphere compared to the northern during 


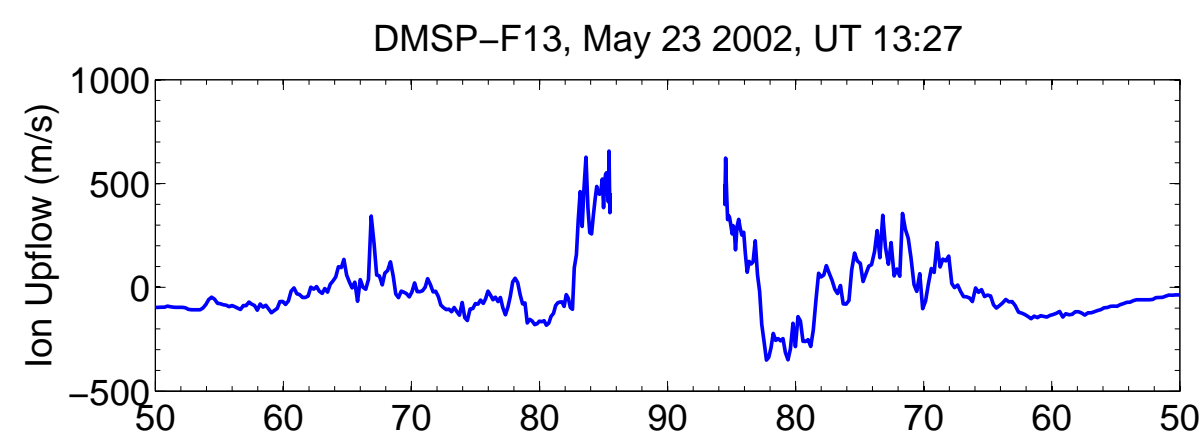

CHAMP, May 23 2002, UT 13:30

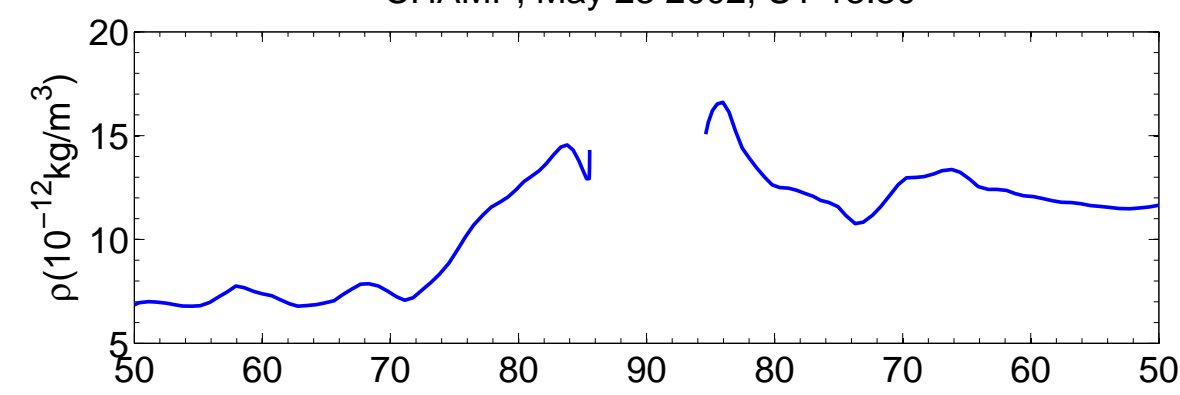

CHAMP, May 23 2002, UT 13:30

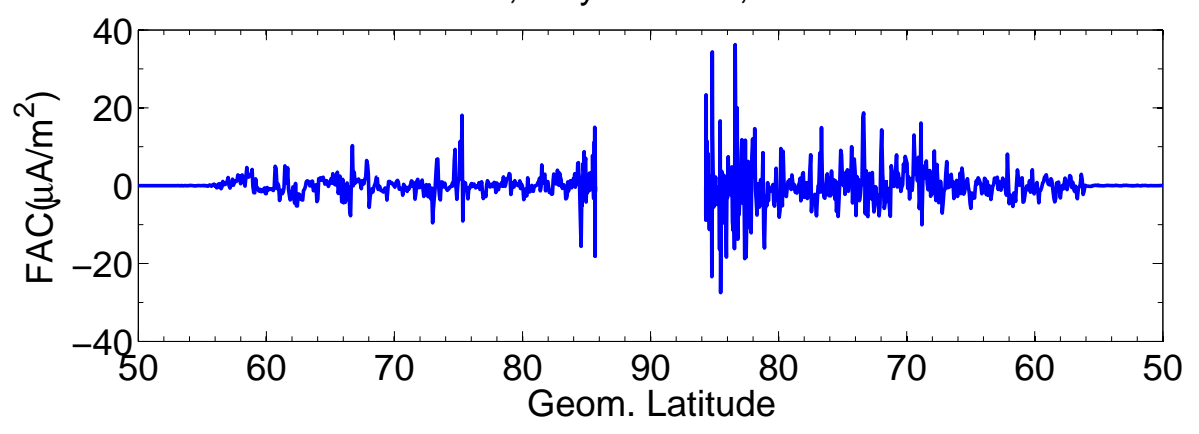

Fig. 13. Ion upflow observed by DMSP-F13 (top) at $840 \mathrm{~km}$ altitude compared to density anomaly (middle) and FAC density (bottom) observed by CHAMP at almost the same time and latitude. The lower two panels are the same as shown in Fig. $6 \mathrm{~b}$.

the months around June solstice. The difference between the detection rates may just be a consequence of the larger offset of the southern geomagnetic pole. Lühr et al. (2007) have shown in their Fig. 2 that CHAMP samples the northern polar cap region twice as dense as the southern.

The typical scale size of the anomaly is about $700 \mathrm{~km}$, which makes it a rather localized phenomenon. Prevailing ambient conditions such as FACs, electron density or electron temperature are generally not confined to the enhanced region, which suggests that some other mechanisms must be responsible for the local uplift of the atmosphere.

\subsection{Suggestions for driving mechanisms}

A classical mechanism for atmospheric up-lift is Joule heating. For the cusp-related mass density anomalies Rentz and
Lühr (2008) have identified Joule heating as the most likely driving process. For depositing the energy in the thermosphere field-aligned currents and particle precipitation are vital candidates. Our extensive survey revealed that about half of the anomaly events are not accompanied by FACs, which means that other processes must also be considered. Bruinsma and Forbes (2007) found that large scale traveling atmospheric disturbances sometimes propagate across the polar cap. Based on the density variations along CHAMP orbit, some density peaks in the polar cap are found accompanied by depletions at one or both sides. This suggests that transpolar propagation could be an explanation. In recent years it has been observed that during great storms large amounts of plasma are convecting from the day to the night side via the polar cap (e.g. Stolle et al., 2006, and references therein). When crossing such a tong of dense plasma a local peak 
in electron density is recorded. The drifting dense plasma could help to move, due to the enhanced collision frequency, up-welling air from the cusp into the polar cap. Also winds can have an influence on the density distribution. We would, however, need wind observations for assessing their contribution.

Another mechanism for atmospheric upwelling is the ion upflow at high latitudes. It has been known for quite some times that during magnetically disturbed periods $\mathrm{H}+$ and $\mathrm{O}+$ ions are accelerated upward and leave the atmosphere along the field lines (see Pollock et al., 1990, for an overview). Due to ion-neutral collision this can set up a vertical motion of neutral particles and cause local density enhancements. Obviously, this mechanism is also effective for our density anomalies. We found one event where the ion upflow features observed by DMSP match very well the mass density enhancement detected by CHAMP (see Fig. 13). At the same location also intense FACs are observed. A detailed discussion of this driving mechanism goes, however, beyond the scope of this study. Herein, we just wanted to point out the coexistence of these phenomena.

Further studies are needed for identifying the roles of the different driving mechanisms for the storm-time mass density anomalies in the polar cap.

\section{Summary}

We have presented observations of mass density anomalies in the polar cap region during geomagnetic storms. Practically, in each of the 29 major storms in 2002-2005 strong thermospheric mass density enhancements were detected by CHAMP at about $400 \mathrm{~km}$. Characteristic features observed are:

1. The anomalies are of medium scale size (typically $<900 \mathrm{~km})$ and seem to have a short dwell time $(<1.5 \mathrm{~h})$ in the polar cap.

2. The ratio of density enhancement, on average by a factor of 2, shows little dependence on the solar flux level (F10.7).

3. The peak density in the Northern Hemisphere is by a factor of 1.4 larger than in the southern. However, the relative enhancement is comparable in both hemispheres.

4. Mass density anomalies in the polar cap occur under all interplanetary magnetic field (IMF) directions. They show some preference for a southward IMF orientation or for strong northward. No clear local time dependence on IMF orientation is observed.

5. About half of the anomalies are accompanied by strong FAC for northward IMF.
6. Some density anomalies are accompanied by intense ion upflows, which could be a possible cause for the density enhancement. The local mass density anomaly in the polar cap during storm time is a complex phenomenon. There are probably several different mechanisms responsible for their formation.

Acknowledgements. We thank Matthias Förster for providing the ACE data, Stefanie Rentz for the CHAMP mass density data and Patricia Ritter for the FAC data. The operational support of the CHAMP mission by the German Aerospace Centre (DLR) and the financial support for the data processing by the Federal Ministry of Education and Research (BMBF), as part of the Geotechnology Programme, are gratefully acknowledged. One of the authors $(\mathrm{Ru}-$ osi Liu) is supported by the German Academic Exchange Service (DAAD).

Topical Editor C. Jacobi thanks two anonymous referees for their help in evaluating this paper.

\section{References}

Bruinsma, S., Tamagnan, D., and Biancale, R.: Atmospheric densities derived from CHAMP/STAR accelerometer observations, Planet. Space Sci., 52, 297-312, 2004.

Bruinsma, S., Forbes, J. M., Nerem, R. S., and Zhang, X.: Thermospheric density response to the 20-21 November 2003 solar and geomagnetic storm from CHAMP and GRACE accelerometer data, J. Geophys. Res., 111, A06303, doi:10.1029/2005JA011284, 2006.

Bruinsma, S. and Forbes, J. M.: Global observation of traveling atmospheric disturbances (TADs) in the thermosphere, Geophys. Res. Lett., 34, L14103, doi:10.1029/2007GL030243, 2007.

Burke, W. J., Huang, C. Y., Marcos, F. A., and Wise, J. O.: Interplanetary control of thermospheric densities during large magnetic stroms, J. Atmos. Solar-Terr. Phys., 69, 279-287, 2007.

Burns, A. G., Killeen, T. L., Carignan, G. R., and Roble, R. G.: Large enhancements in the $\mathrm{O} / \mathrm{N}_{2}$ ratio in the evening sector of the winter hemisphere during geomagnetic storms, J. Geophys. Res., 100, 14661-14671, 1995.

Cooke, D. L., Turnbull, W., Roth, C., Morgan, A., and Redus, R. Ion drift-meter status and calibration, in: First Champ Mission Results for Gravity, Magnetic, and Atmospheric Studies, edited by: Reigber, C., Lühr, H., and Schwintzer, P., Springer, New York, pp. 212-219, 2003.

Crowley, G., Immel, T. J., Hackert, C. L., Craven, J., and Roble, R. G.: Effect of IMF By on thermospheric composition at high and middle latitude: 1. Numerical experiments, J. Geophys. Res., 111, A10311, doi:10.1029/2005JA011371, 2006.

Forbes, J. M., Gonzalez, R., Marcos, F. A., Revelle, D., and Parish, H.: Magnetic storm response of lower thermosphere density, J. Geophys. Res., 101, 2313-2319, 1996.

Forbes, J. M., Lu, G., Bruinsma, S., Nerem, R. S., and Zhang, X. Thermosphere density variations due to the 15-24 April 2002 solar events from CHAMP/STAR accelerometer measurements, J. Geophys. Res., 110, A12S27, doi:10.1029/2004JA010856, 2005.

Förster, M., Rentz, S., Köhler, W., Liu, H., and Haaland, S. E.: IMF dependence of high-latitude thermospheric wind pattern derived from CHAMP cross-track measurements, Ann. Geophys., 
26, 1581-1595, 2008,

http://www.ann-geophys.net/26/1581/2008/.

Heppner, J. P. and Maynard, N. C.: Empirical high-latitude electric field models, J. Geophys. Res., 92, 4467-4489, 1987.

Kwak, Y.-S., Richmond, A. D., Deng, Y., Forbes, J. M., and Kim, K.-H.: Dependence of the high-latitude thermospheric densities on the interplanetary magnetic field, J. Geophys. Res., 114, A05304, doi:10.1029/2008JA013882, 2009.

Liu, H., Lühr, H., Henize, V., and Köhler, W.: Global distribution of the thermospheric total mass density derived from CHAMP, J. Geophys. Res., 110, A04301, doi:10.1029/2004JA010741, 2005.

Liu, H. and Lühr, H.: Strong disturbance of the upper thermospheric density due to magnetic storms: CHAMP observations, J. Geophys. Res., 110, A09S29, doi:10.1029/2004JA010908, 2005.

Liu, H., Lühr, H., Watanabe, S., Köhler, W., Henize, V., and Visser, P.: Zonal winds in the equatorial upper thermosphere: Decomposing the solar flux, geomagnetic activity, and seasonal dependencies, J. Geophys. Res., 111, A07307, doi:10.1029/2005JA011415, 2006.

Liu, H., Lühr, H., and Watanabe, S.: Climatology of the equatorial thermospheric mass density anomaly, J. Geophys. Res., 112, A05305, doi:10.1029/2006JA012199, 2007.

Lühr, H., Rother, M., Köhler, W., Ritter, P., and Grunwaldt, L.: Thermospheric up-welling in the cusp region: Evidence from CHAMP observations, Geophys. Res. Lett., 31, L06805, doi:10.1029/2003GL019314, 2004.

Lühr, H., Rentz, S., Ritter, P., Liu, H., and Häusler, K.: Average thermospheric wind patterns over the polar regions, as observed by CHAMP, Ann. Geophys., 25, 1093-1101, 2007,

http://www.ann-geophys.net/25/1093/2007/.

McComas, D, J., Bame, S. J., Barker, P., Feldman, W. C., Phillips, J. L., Riley, P., and Griffee, J. W.: Solar wind Electron Proton Alpha Monitor (SWEPAM) for the Advanced Composition Explorer, Space Sci. Rev., 96, 563-612, 1998.

McNamara, L. F., Cooke, D. L., Valladares, C. E., and Reinisch, B. W.: Comparision of CHAMP and Digisonde plasma frequencies at Jicamarca, Peru, Radio Sci., 42, RS2005, doi:10.1029/2006RS003491, 2007.

Müller, S., Lühr, H., and Rentz, S.: Solar and magnetospheric forcing of the low latitude thermospheric mass density as observed by CHAMP, Ann. Geophys., 27, 2087-2099, 2009, http://www.ann-geophys.net/27/2087/2009/.

Pollock, C. J., Chandler, M. O., Moore, T. E., Waite Jr., J. H., Chappell, C. R., and Gurnett, D. A.: A survey of upwelling ion event characteristics, J. Geophys. Res., 95, 18969-18980, 1990.

Prölss, G. W.: Magnetic Storm Associated Perturbations of the Upper Atmosphere, in: Magnetic Storms, vol. 98, edited by: Tsurutani, B. T., Gonzalez, W. D., Kamide, Y., and Arballo, J. K., AGU Geophysical Monograph, pp. 227, 1997.
Rentz, S. and Lühr, H.: Climatology of the cusp-related thermospheric mass density anomaly, as derived from CHAMP observations, Ann. Geophys., 26, 2807-2823, 2008, http://www.ann-geophys.net/26/2807/2008/.

Richmond, A. D.: Ionospheric electrodynamics using magnetic apex coordinates. J. Geomagn. Geoelectr., 47, 191-212, 1995.

Rother, M., Schlegel, K., and Lühr, H.: CHAMP observation of intense kilometer-scale field-aligned currents, evidence for an ionospheric Alfvén resonator, Ann. Geophys., 25, 1603-1615, 2007 , http://www.ann-geophys.net/25/1603/2007/.

Schlegel, K., Lühr, H., St.-Maurice, J.-P., Crowley, G., and Hackert, C.: Thermospheric density structures over the polar regions observed with CHAMP, Ann. Geophys., 23, 1659-1672, 2005, http://www.ann-geophys.net/23/1659/2005/.

Smith, C. W., L'Heureux, J., Ness, N. F., Acuna M. H., Burlaga, L. F., and Scheifele, J.: The ACE magnetic field experiment, Space Sci. Rev., 86, 613-632, 1998.

Stolle, C., Lilensten, J., Schlüter, S., Jacobi, Ch., Rietveld, M., and Lühr, H.: Observing the north polar ionosphere on 30 October 2003 by GPS imaging and IS radars, Ann. Geophys., 24, 107113,2006 , http://www.ann-geophys.net/24/107/2006/.

Sutton, S. K., Frobes, R. S., and Nerem, R. S.: Global thermospheric neutral density and wind response to the severe 2003 geomagnetic storms from CHAMP accelerometer data, J. Geophys. Res., 110, A09S40, doi:10.1029/2004JA010985, 2005.

Vennerstrom, S., Moretto, T., Olsen, N., Friis-Christensen, E., Stampe, A. M., and Watermann, J.: Field-aligned currents in the dayside cusp and polar cap region during northward IMF, J. Geophys. Res., 107, A81188, doi:10.1029/2001JA009162, 2002.

Wang, H., Lühr, H., and Ma, S. Y.: Solar zenith angle and merging electric field control of field-aligned currents: A statistical study of the southern hemisphere, J. Geophys. Res., 110, A03306, doi:10.1029/2004JA010530, 2005.

Wang, H., Ridley, A. J., and Lühr, H.: SWMF simulation of fieldaligned currents for a varying northward and duskward IMF with nonzero dipole tilt, Ann. Geophys., 26, 1461-1477, 2008, http://www.ann-geophys.net/26/1461/2008/.

Weimer, D. R., Ober, D. M., Maynard, N. C., Collier, M. R., McCormas, D. J., Ness, N. F., Smith, C. W., and Watermann, J.: Predicting interplanetary magnetic field (IMF) propagation delay times using the minimum variance technique, J. Geophys. Res., 108(A1), 1026, doi:10.1029/2002JA009405, 2003.

Zhang, J., Richardson, I. G., Webb, D. F., Gopalswamy, N., Huttunen, E., Kasper, J. C., Nitta, N. V., Poomvises, W., Thompson, B. J., Wu, C.-C., Yashiro, S., and Zhukov, A. N.: Solar and interplanetary sources of major geomagnetic storms (Dst $<=$ -100 nT) during 1996-2005, J. Geophys. Res., 112. A10102, doi:10.1029/2007JA012321, 2007. 